\title{
A cosmologia negra para os estudos de comunicação e música ${ }^{12}$
}

\author{
Black cosmology for the studies of communication and music
}

Cosmología negra para los estudios de comunicación y música

Tobias Arruda Queiroz - Universidade do Estado do Rio Grande do Norte | Faculdade de Filosofia e Ciências Sociais, Departamento de Comunicação Social | Mossoró | RN | Brasil. E-mail: tobiasqueiroz@gmail.com | ㄱorcio

Resumo: Este trabalho tem o objetivo de refletir a potência em se desenvolver uma perspectiva decolonial para se pensar as manifestações urbanas da cena musical de Will Straw e contribuir, desta forma, para os estudos de Comunicação e Música, bem como, para o campo da Educação. Para isso, tomamos como ponto de partida o Valhalla Rock Bar da cidade de Mossoró-RN. Observamos assim a possibilidade de ampliarmos a epistemologia, o campo de análise e de reflexão ao incluirmos elementos da cosmologia negra e, assim, não restringirmo-nos às epistemologias eurocentradas e norte-americanas. Desta forma, diferentemente de outras análises de cena musical global, pudemos identificar características e peculiaridades endógenas, bem como, possibilitamos aberturas para se pensar outras manifestações culturais e outros perfis identitários, que não sejam restritos à cultura masculina e branca tão comum a bares como o Valhalla.

Palavras-chave: Cena musical decolonial. Heavy metal. Valhalla.

Abstract: This work aims to reflect the power to develop a decolonial perspective to think about the urban manifestations of the music scene by Will Straw and thus contribute to the studies of Communication and Music, as well as to the field of education. For this, we take as a starting point the Valhalla Rock Bar of the city of Mossoró-RN. We thus observe the possibility of extending epistemology, the field of analysis and reflection by including elements of black cosmology and thus not restricting ourselves to Eurocentric and North American epistemologies. Thus, unlike other analyzes of the global music scene, we were able to identify endogenous characteristics and peculiarities, as well as allowing openings to think about other cultural manifestations and other identity profiles, which are not restricted to the male and white culture so common to bars like Valhalla.

Keywords: Decolonial music scene. Heavy metal. Valhalla.

\footnotetext{
${ }^{1}$ Este artigo integra a minha tese doutoral "Valhalla, All Black In e Metal Beer: repensando a cena musical a partir dos bares no interior do Nordeste", defendida em abril de 2019 no Programa de Pós-Graduação em Comunicação. Destaco também a participação enquanto bolsista e pesquisador visitante na Universidade do Porto, através do programa de cooperação internacional CAPES/FCT (Fundação para a Ciência e Tecnologia).

${ }^{2} \mathrm{O}$ artigo aqui publicado é uma versão editada, revisada e ampliada do trabalho apresentado no $42^{\circ}$ Congresso Brasileiro de Ciências da Comunicação - Intercom, 2012, Belém. Para (re) pensar a noção de Cena Musical. São Paulo: Intercom, 2019. Disponível em: http://portalintercom.org.br/anais/nacional2019. Acesso em: 10 de novembro de 2019.
}

- Recebido em 21 de novembro de 2019 • Aprovado em 11 de março de 2020 • e-ISSN: 2177-5796

DOI: http://dx.doi.org/10.22483/2177-5796.2020v22n2p455-472

Copyright @ 2019. Conteúdo de acesso aberto, distribuído sob os termos da Licença Internaonal da CreativeCommons - CC BY-NC-SA Atribuição Não Comercial (https://br.creativecommons.org/licencas/) - Permite distribuição e reprodução, desde que atribuam os devido créditos à publicação, ao autor(es) e que licenciem as novas criações sob termos idênticos. 
Resumen: Este trabajo tiene como objetivo reflejar el poder de desarrollar una perspectiva descolonial para pensar sobre las manifestaciones urbanas de la escena musical por Will Straw y contribuir así a los estudios de Comunicación y Música, así como a la campo de la educación Para ello, tomamos como punto de partida el Valhalla Rock Bar de la ciudad de Mossoró-RN. De este modo, observamos la posibilidad de extender la epistemología, el campo de análisis y la reflexión al incluir elementos de la cosmología negra y no limitarnos a las epistemologías eurocéntricas y norteamericanas. Por lo tanto, a diferencia de otros análisis de la escena musical global, pudimos identificar características y peculiaridades endógenas, así como permitir que las aperturas piensen en otras manifestaciones culturales y otros perfiles de identidad, que no están restringidos a la cultura masculina y blanca tan común en bares como Valhalla.

Palabras clave: Escena musical descolonial. Heavy metal. Valhalla. 


\section{Introdução}

Para o desenvolvimento deste nosso trabalho, temos como ponto de partida o entendimento da presença colonial e da estrutura racial, germinada durante o período escravocrata e, infelizmente, ainda presente nos dias atuais, para provocarmos epistemologicamente o fazer científico no Brasil e, assim, ressoar por provocações no campo das educações e suas dimensões. Tomamos como recorte os estudos de Comunicação, no nosso caso específico as sub áreas a englobar a Comunicação e a Música. A nossa observação dialoga e, ao mesmo tempo, não difere da realidade do recorte racial dos outros cursos de graduação no Brasil. Ou seja, em poucas palavras, podemos afirmar sobre a existência de uma relação direta entre maior escolaridade e uma menor presença de pessoas negras. Segundo dados do censo realizado pelo Instituto Nacional de Estudos e Pesquisas Educacionais Anísio Teixeira (Inep), em informações divulgada na página do sistema Globo em 2017, havia, entre instituições públicas e privadas, mais de 400 mil docentes em sala de aula, destes apenas 62 mil, ou seja, 16\% do total se autodeclaram pessoas negras (MORENO, 2018). Levando em consideração que a formação do pesquisador passa obrigatoriamente pelo alto grau de instrução, temos assim, uma ínfima presença de pessoas negras nos programas de pós-graduação brasileira.

Estas premissas não se configuram como mera retórica. Elas nos apontam e materializam as desigualdades sociais e econômicas na formação educacional, como também, a sua consequência nas faixas de maiores titulações acadêmicas. Temos, desta forma, quando há sua presença, um sistemático isolamento da/o pesquisador/a negro/a na academia. Como consequência desta nefasta lacuna política, embora tenha sido amenizada com as recentes políticas de ações afirmativas, perdura a insuficiência, segundo os dados do censo do Inep, para emular na academia e na pesquisa boa parte da proporcionalidade e divisão étnica da população nacional.

Sendo assim, apresentamos como objetivo neste artigo questionarmos alguns pressupostos reverberados na academia e em algumas pesquisas, que insistem em buscar uma certa homogeneidade ao se falar dos atores a circundar os espaços onde há escuta coletiva de músicas de determinados gêneros musicais, principalmente os conectados à cultura anglo-saxã, como o heavy metal, por exemplo. Buscamos, assim, apresentar um estudo de caso, em que investigamos 
a materialização da cena metal numa cidade no interior do Nordeste, porém sem partir necessariamente de alguns estudos canônicos na área, observamos a necessidade de repensarmos algumas noções de cena musical e ampliar nosso escopo a partir da visão transcultural do signo de Exu, (RUFINO, 2016), bem como apresentar os primeiros ensaios daquilo que nomeamos enquanto Cena Musical Decolonial.

Com este intuito em mente estruturamos este artigo em quatro partes. O nosso próximo tópico apresenta teoricamente a noção de cena musical a partir do sociólogo canadense Will Straw (1991, 2001, 2012). Discutimos como um conceito nativo, ou seja, oriundo das ruas e dos atores envolvidos com a cena foi teorizado e, bem articulado, através de Straw. Na sequência apresentamos a nossa busca em outro lugar ao sul: rotas de fugas geopolíticas possíveis para se pensar a cena musical. Este tópico se configura uma continuação do anterior, porém apresentando o estado da arte em outros países - que não se restringem, diga-se - aos euro-norte-americanos. Na segunda metade da nossa proposta temos como terceiro tópico a apresentação do bar Valhalla, da cidade de Mossoró/RN, para nos ajudar a ilustrar e a enfrentar as problemáticas aqui levantadas. Por fim, nas nossas considerações, apresentamos algumas proposições decoloniais da cena musical com ecos pelas educações.

\section{Cena musical}

Há alguns elementos nos estudos de cena que nos inquietam ao ponto de não nos identificarmos com algumas premissas. A principal delas é a centralidade em boa parte dos estudos em grandes cidades globais. Transmite-se assim a sensação de "algo a ser seguido" ou de um "modelo ideal" para que se possa enxergar a partir dos próprios atores e de inúmeros investigadores e acadêmicos, o título de cena musical. Ou seja, a existência prévia de uma espécie de arcabouço subjetivo de estrutura e de infraestrutura mínima para visualizar o fenômeno enquanto tal.

O pontapé para estas discussões ganharem cores vibrantes no universo acadêmico foi o seminal trabalho de Will Straw (1991). Neste artigo, Straw reflete a partir de um conceito nativo, presente tanto nas ruas, quanto na mídia especializada em cobrir eventos culturais, o termo "cena". O pesquisador canadense desenvolve, a partir de então, ao ouvir estas vozes a noção de "cena musical", priorizando a interconexão de elementos musicais, como o gênero musical com a espacialidade. 
Além desse ponto de destaque, há outro importante tópico para melhor entender e aplicar, quando necessário, a noção de cena para investigar a cultura musical de determinado espaço: a fluidez inerente aos frequentadores, a qual difere da ideia de comunidade, até então predominante em alguns estudos acadêmicos vigente à época. Esses dois tópicos são os mais recorrentes em estudos de cena nas décadas posteriores. Trabalhos interessantes que articulam a geografia com o consumo de música mostram-nos como é potente essa articulação identitária.

Numa tentativa de melhor compreender a proposição de Will Straw, devemos ficar atentos, entre outros tópicos, a um autor particularmente presente no trabalho embrionário sobre cenas musicais: Edward W. Said (1990), de onde o pesquisador canadense inspirou-se para utilizar o termo system of articulation, logic of change, também presente no título do artigo seminal.

O trabalho de Said, citado por Straw (1991), é o Figures, configurations, transfigurations (1990). Veiculado inicialmente na revista Race \& Class, este texto repercute alguns elementos de uma outra importante publicação do mesmo autor, Orientalismo (1978 [2003]), ou seja, “cultura, ideias, história e poder" (SAID, 2003)³. O início deste artigo de Said (2003) é uma contextualização da presença maciça do idioma anglo-saxão em determinados espaços, desde aviação comercial a instituições financeiras; da tecnologia e, mais adiante, em inúmeros outros meios de comunicação. Dessa forma, o autor ilustra o que ele denominou de "sistema de articulação universal”, utilizando exemplos da literatura, sua área de atuação na universidade de Columbia, em Nova York, reivindicando espaços intelectuais e reflexivos para se pensar além de discursos essencialistas. Will Straw (1991) refez essa leitura a partir da perspectiva da música e afirmou:

Se o status do local foi transformado dentro das sociedades contemporâneas, isso é em parte através do funcionamento do que Edward Said chamou de 'sistema cada vez mais universal de articulação' (Said, 1990: 8). Este 'sistema' é, obviamente, moldado pela

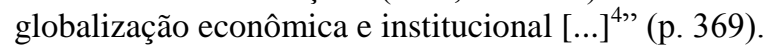

\footnotetext{
${ }^{3}$ Este trecho foi retirado do prefácio de Orientalismo, edição de bolso, publicado no Brasil pela Companhia das Letras.

${ }^{5}$ Todas as traduções neste trabalho foram realizadas por mim. "If the status of the local has been transformed within contemporary societies, this is in part through the workings of what Edward Said has called an 'increasingly universal system of articulation' (SAID, 1990, p. 8). This 'system' is, obviously, shaped by economic and institutional globalization, and it is the task of a critical political economy to account for its effects (Paul Rutten's paper pages 292-303 in this issue offers useful tools for doing so)".
} 
Em outras palavras, e mais uma vez, observando a afirmação de Said (1990), devemos ficar atentos ao "mapa do sistema mundial, articulando e produzindo cultura, economia e poder político" (p. 8). Pois, ainda segundo o autor, esse sistema também tem desenvolvido uma "tendência institucionalizada para produzir imagens transnacionais fora de escala que estão agora em processo de reorientação de discursos e processos sociais internacionais" "5 (p. 8). Essa última afirmação de Edward Said refere-se, por exemplo, ao coro praticamente uníssono sobre a emergência de imagens sobre o terrorismo e fundamentalismo, durante a década de 1980, a partir de polos midiáticos e metropolitanos, como Washington e Londres. Além disso, afirma Said, "são imagens terríveis que parecem não ter conteúdo ou definições discriminatórias, e significam poder moral e aprovação para quem os usa, defensividade moral e criminalização para quem os designa" (SAID, 1990, p. 9). Dessa forma, o teórico palestino aponta a utilização dos discursos para a criação de espaços hierárquicos e para a formação de palavras-chaves reducionistas, limitando-nos, de certa maneira, a expandir as investigações e olhares para outros territórios que ultrapassem a ideia construída pelo "sistema de articulação universal" calcado na ideia eurocêntrica e norte-americana.

O que estou falando é, portanto, uma forma de considerar o mundo inteiro em que vivemos tão acessível à nossa investigação e interrogatório, sem recursos para chaves mágicas, nem para jargões e instrumentos especiais, nem para práticas cortadas. Como um exemplo de como procederíamos depois de reconhecer essas coisas, existe o padrão implícito em Hobsbawm e Ranger, The Invention of Tradition, que sugere que é um empreendimento intelectual coerente considerar que todas as partes da história humana estão disponíveis para entender e elucidação porque eles são construídos e projetados humanamente para realizar tarefas reais no mundo real. História e geografia são susceptíveis de inventários, em outras palavras (SAID, 1990, p. 11).

Nesse ponto, vale a pena salientar uma parte da atividade política de Edward Said, no qual ele se notabilizou, entre outras atividades, enquanto intelectual ativista, principalmente ao integrar o Conselho Nacional da Palestina, onde, por diversas vezes, criticava publicamente Israel e os países árabes, especialmente ao se referir às políticas mulçumanas que legislavam contra o interesse nacional dos palestinos. Em boa parte do seu trabalho, Edward Said denuncia a forma com que os países árabes, a religião mulçumana e outras manifestações culturais da região são vistas a partir de um discurso fortemente veiculado nos países ditos ocidentais, o que, consequentemente, rendia sempre um olhar do "ocidental". Foi assim com seu trabalho mais

\footnotetext{
${ }^{5}$ Todas as citações do trabalho de Edward Said (1990) foram traduzidas por mim.
} 
famoso, o livro Orientalismo, em que Said (2003) investigou o discurso de alguns produtos culturais veiculados principalmente na Europa. E foi assim também com o texto inspirador de Straw (1991), no qual o pesquisador canadense chama-nos a atenção para alguns dos elementos apontados por Said.

Essas transformações exigem, daqueles que estudam música popular, mais do que gestos bem intencionados na direção da diversidade multicultural. Elas convidam a atenção para as lógicas distintivas de mudança e formas de valorização características de diferentes práticas musicais, uma vez que estas são divulgadas através de suas respectivas comunidades culturais e locais institucionais. Dois exemplos específicos desse sistema de articulação - as características das culturas do rock alternativo e da dance music [...]. Em cada caso, e talvez sem surpresa, pode-se encontrar relações distintivas entre o localismo, como um valor musical e, o sistema de articulação do qual Said fala (STRAW, 1991, p. 369).

Nesta parte do ensaio de Straw (1991), é salutar destacar a leitura que o autor faz em relação às transformações ocorridas dentro do "sistema de articulação institucional global e da economia". Uma delas mora nas "formas de valorização características de diferentes práticas musicais", no que ele aponta para as apropriações realizadas pelas suas "respectivas comunidades culturais". Sobre a influência deste "sistema de articulação", Will Straw comenta que, ao mesmo tempo em que manifestações como o folk-rock de Quebec e o country-rock anglo-canadense surgem, elas estão inseridas mundialmente, "dentro de contextos industriais e culturais internacionais", mesclando-se consequentemente a alguns significados locais, resultando, assim, em um "entrelaçamento de tendências locais e transformações cíclicas nas indústrias internacionais de música” (STRAW, 1991, p. 369-370).

Esse ponto de vista de Straw (1991) ganha robustez ao associar a lógica de mudanças contínuas das indústrias ao "sentido de uma lógica de movimentos circunstanciais", de Michel de Certeau (2008). O trabalho de Certeau (2008) prima pela reapropriação das ações e dos espaços físicos, que, nas palavras do pesquisador francês, está na "arte do fazer" e das "estratégias" e "táticas" nas quais o indivíduo é fruto das suas relações sociais. Ou seja, tudo é voltado às práticas sociais para melhor compreender o indivíduo, que (re)inventa a cultura no cotidiano, utilizando, de forma perspicaz, estratégias, táticas e astúcias.

Por essa perspectiva, as cenas musicais estão dentro do sistema global das indústrias culturais e, ao mesmo tempo, estão passíveis de reapropriações dentro das suas respectivas comunidades, onde os atores podem fazer uma releitura ou uma ressignificação das atividades 
musicais oriundas de outros países. A força que brota desta percepção está nas práticas sociais territorializadas e revistas dentro de um ethos subjetivo da sociedade local. Tais práticas são partes dos ingredientes que nos motivam a investigar e buscar melhor compreender certas relações sociais, tendo a música como componente. Por outro lado, podemos também visualizar e também nos questionar, em uma rápida observação, que a cena musical fica à mercê das forças globais institucionalizadas. Se essa premissa se confirmar, será que só poderemos ter uma possível formação de cena musical - mesmo atendendo a todos os outros elementos da noção - se e somente se estivermos dentro de uma lógica de reapropriação de uma cultura globalizada?

\section{Alguns caminhos possíveis}

Numa busca em romper com esta linha de raciocínio a evocar sempre a ideia hierarquizante do cosmopolitismo, ou do "cosmopolitismo estético" (REGEV, 2013), sugerimos observar alguns pequenos espaços sem essa lógica predefinida macroestruturalmente. Alguns pesquisadores já puseram isso em prática, de certa forma. Apesar de termos uma determinada hegemonia geopolítica na memória e na produção de material, há alguns estudos de cenas musicais além das fronteiras do dito "primeiro mundo", recentemente concretizados.

Temos, desde produções audiovisuais a abordarem alguns países fora do grande circuito financeiro, como o "Global Metal”, realizado pelo antropólogo e músico canadense Sam Dunn ${ }^{6}$ e o diretor e produtor também canadense Scot McFadyen, como também o curioso documentário "Heavy Metal in Baghdad" (SANT, 2015) do canadense Eddy Moretti e do canadensepaquistanês Surosh Alvi, o qual acompanha a rotina da única banda de metal do Iraque, a Acrassiacauda.

Temos também outros documentários, tanto realizados por investigadores quanto por programas de TV. O primeiro deles, “The Distorted Island: Heavy Metal music and community in Puerto Rico, foi lançado em 2015 e produzido por Nelson Varas-Díaz (2015), professor, investigador e diretor do "Porto Rico Heavy Metal Studies Program", juntamente a Osvaldo

\footnotetext{
${ }^{6}$ Sam Dunn é um autodeclarado "headbanger", e é bem conhecido no meio por dirigir outros registros audiovisuais, incluindo documentários/shows do mundo do metal. Em 2005 lançou "A Headbanger's Journey” onde relata a saga de alguns fãs do metal, já em 2011 lança "Iron Maiden's Flight 666" um registro da turnê da banda britânica em 23 apresentações realizadas nos cinco continentes em apenas 45 dias. Todos estes registros transmitem a noção da globalidade do heavy metal e, ao mesmo tempo, apresentam e ajudam a difundir os signos presentes da cultura do metal.
} 
González-Sepúlveda, Eliut Rivera-Segarra e Sigrid Mendoza. E, mais recentemente, em 2017, foi lançado o documentário "Islamic metal band in Indonesia - The Westerners" (VPRO WORLD SERIES, 2018). Apresentado em formato jornalístico pela holandesa Eva Cleven para o programa educativo voltado para o público juvenil "Het Klokhuis", da TV NTR, o registro acompanha a rotina da banda de metal "Purgatory" em um país com a presença de mais de 200 milhões de mulçumanos, bem como a rotina e o universo dos sete membros da banda e seus respectivos pontos de vista, entre os quais se criticam valores disseminados pelos países ditos ocidentais, como a democracia, emancipação das mulheres, bem-estar animal e a liberdade religiosa.

Nessa breve vista, podemos perceber investigações e registros de características de

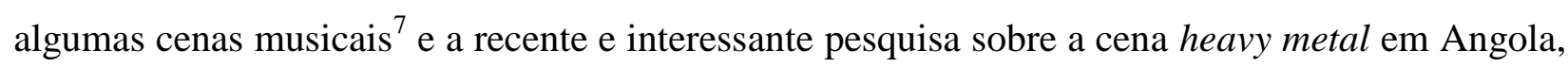
realizada pela investigadora brasileira Melina Santos (2018). Uma excelente contribuição, sem sombra de dúvida; porém, somente em duas delas (Porto Rico e Angola), foram realizadas por pesquisadores/a não anglófonos e/ou euro-norte-americanos.

Então, dada essa configuração, como poderíamos observar a formação de cenas musicais em outros eixos geográficos e em outras condições socioeconômicas e políticas? Como podemos refletir sobre a possibilidade de haver cena musical ou não e, principalmente, qual sua importância para os atores locais? Será que um bar, localizado numa cidade sem aeroportos e com pouco ou nenhum show de bandas de metal, tem alguma importância nesse circuito global? Será que podemos repensar a existência de cena musical, além de alguns pressupostos estandartizados? E, como essas tensões podem nos possibilitar outros pensamentos por outras paragens em pesquisas e(m) educação tão envolvidas com as estandartizações?

\section{Um bar de metal no interior do Nordeste}

O Valhalla Rock Bar existe há mais de treze anos, na cidade interiorana de Mossoró no Estado do Rio Grande do Norte', sempre tocando metal e seus subgêneros. Disponibiliza aos seus clientes mesas e cadeiras as quais ficam distribuídas na calçada destinada ao pedestre e em boa parte da rua, onde acabam por disputar espaço com os poucos veículos que por ali transitam. As

\footnotetext{
${ }^{7}$ Os exemplos citados no parágrafo anterior referem-se a países como Bangladesh, Tunísia, Indonésia, Iraque e Porto Rico, num aparente rompimento com a lógica eurocêntrica, no entanto, deve-se sublinhar ainda o predomínio anglófono destas produções e consequentemente um distanciamento geopolítico com o local da produção.
} 
mesas vêm normalmente acompanhadas de cervejas geladas e, como costuma ocorrer em lugares com esta proposta, preços bem acessíveis. Seu principal petisco é filé com fritas e espetinhos de vários tipos de carne e queijo. Já a trilha sonora é organizada de forma aleatória no YouTube principalmente quando parte de seus frequentadores se revezam ao computador, escolhem seus artistas prediletos e automaticamente os veem na TV de 42" polegadas, conectada no notebook e a uma pequena caixa amplificada, a banda e o gosto da vez. Mas nem sempre foi assim. Quando da abertura do bar a trilha sonora era regida por um aparelho de DVD conectado a uma televisão. A fruição musical estava conectada exatamente pelo suporte físico disponibilizado pela mídia DVD, algo que por si só impõe uma certa limitação de acesso à quantidade de discos acessíveis no momento. Com alguns anos houve a primeira mudança. Um HD externo conectado e preenchido, por alguns frequentadores, com músicas e vídeos das bandas. Esse foi o primeiro passo para uma digitalização mais ampliada do que a mídia anterior. O modelo atual tem pouco mais de dois anos - com a inclusão da internet. Mais precisamente em agosto/2016, iniciou-se as transações comerciais também por cartão de crédito, na tentativa de diminuir a inadimplência ${ }^{8}$. Segundo Toninho a medida ajudou muito, visto que em torno de $40 \%$ das vendas são realizadas via cartão.

A priori, como podemos observar, é um bar como um outro qualquer, o qual poderia estar localizado em qualquer outra cidade do país. Há cervejas, petiscos, músicas e frequentadores assíduos que dão sustentabilidade ao estabelecimento a mais de uma década. Sim, esse pequeno bar está prestes a completar 13 anos de existência! Mas, apesar da sua aparente e despretensiosa existência surgem-nos perguntas as quais nos fazem refletir sobre alguns elementos que transitam em torno da noção de "cena musical" e de outros elementos evocados pelo território "valhallaniano". O entendimento de Território aqui dialoga com a ideia de poder no sentido implícito ou simbólico de apropriação (HAESBAERT, 2014).

A existência do Valhalla nos fez pensar e questionar acerca da valoração dos shows em alguns estudos de cena, pois visualizamos a existência do bar como um importante nódulo necessário para a manutenção de uma rotina, de ritualização e transmissão dos códigos inerentes ao gênero, bem como a ocupação territorial a longo prazo de determinados lugares. Sem o bar, apenas alguns eventos específicos e pontuais na cidade de Mossoró não seriam suficientes para

\footnotetext{
${ }^{8}$ Informação coletada juntamente ao Toninho em conversas informais no Valhalla.
} 
uma autossustentação da cena. A rotina de pessoas frequentadoras do Valhalla, composta por headbangers e não fãs de rock, que ao longo do ano se encontram para ouvir o mesmo tipo de música seja possivelmente mais relevante do que eventos pontuais e muitas vezes são obliterados em alguns estudos.

Figura 1 - Infográfico localização do Valhalla Rock Bar - Mossoró/RN

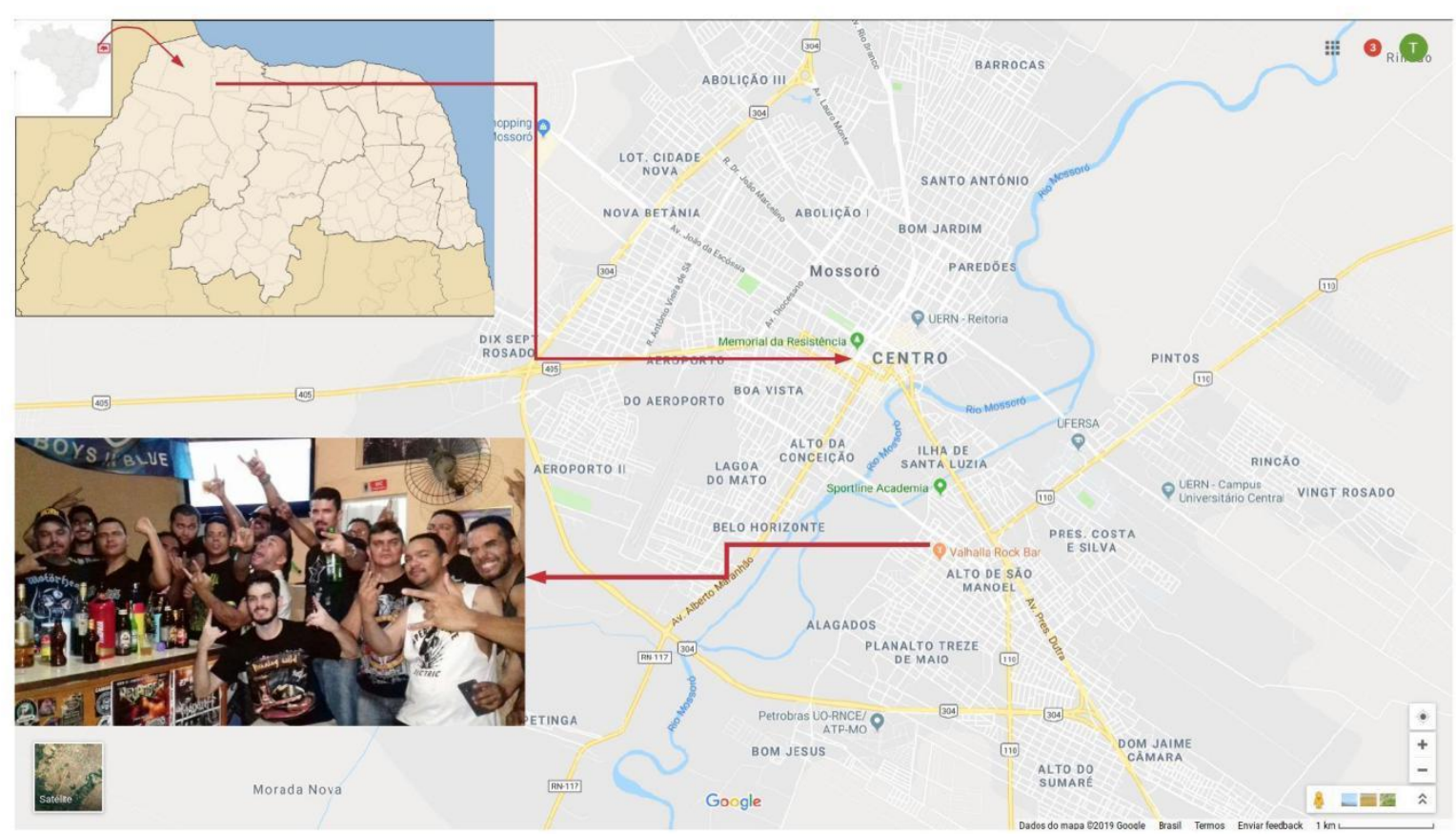

Fonte: Infográfico elaboração própria a partir de imagens do Google Maps, Wikipedia e foto de acervo. O primeiro da esquerda é o proprietário Toninho.

Nesta direção é importante para este trabalho desenvolver essa rede como uma cena cultural, pois como pontua Will Straw (2013), é possível pensar que uma das marcas das cenas é sua capacidade de teatralizar, de colocar em cena (no sentido de mise-en-scène) afetos, objetos, sensibilidades e valores culturais. Nesse sentido, artefatos audiovisuais, cerveja, disposição espacial, frequentadores, mobiliário, proprietários, sites de disponibilização de música stream, tornam-se actantes, ou seja: “[...] o ator da expressão 'ator-rede'. Ele é o mediador, o articulador que fará a conexão e montará a rede nele mesmo e fora dele em associação com outros" (LEMOS, 2013, p. 42). 
QUEIROZ, Tobias Arruda. A cosmologia negra para os estudos de comunicação e música.

Está-se aqui pensando em camadas, ou seja, é possível imaginar que o Valhalla é um lugar que materializa parte da cena musical de heavy metal em Mossoró. Outros exemplos desta rede na cidade é configurada com espaços exclusivos de comercialização de itens voltados ao mundo da música, tais como, a loja de camisetas de bandas de rock e heavy metal a Skayp Alternativa onde o proprietário Edmar Skandurra mantém a loja Skayp Alternativa (SKAYP MODELS, 2013) em um box no Mercado Público Municipal vendendo exclusivamente camisetas de bandas. Já na Galeria Brasil há loja de discos e confraria ocasional dos headbangers a Rising Records (2013). Também podemos citar as bandas mossoroenses "Heavenless" (2015) (religion metal) 9 "Lasting Maze" (2014) (metal melódico) a "RevAnger" (2015) (hard e heavy) e a "Black Witch" (BLACK WITCH, 2015) (bong rock) ${ }^{10}$. Ou seja, como podemos observar o Valhalla, além de teatralizar parte desta cena, integra ao mesmo tempo uma rede que se materializa como uma pequena cena cultural. Partindo da definição ampla que Simone Pereira de Sá desenvolveu em diálogo com o trabalho de Straw (1991, 2001), mantemos a ideia de que qualquer definição mínima de cena pressupõe a existência de uma rede e a afirmação de lugares como modos de significar a cidade.

Outro importante dado em que reforça a nossa hipótese do Valhalla enquanto um nódulo na articulação da rede da cena musical do metal do Estado é o seu papel territorializante, bem como, sua função simbólica ao nomear um festival de metal na cidade de Mossoró/RN há doze edições: o Festival Valhalla. Uma de suas últimas edições foi realizada no dia 21 de outubro de 2017 no clube Cárcara do Asfalto, um privilegiado espaço ao lado do rio Mossoró no centro da cidade e onde também é a sede do motoclube homônimo. No festival houve a participação de quatro bandas, duas delas de death metal escaladas como headline do evento, a Gestos

\footnotetext{
${ }^{9}$ O material de divulgação da banda Heavenless contextualiza a partir da fala dos seus três integrantes os percalços em ser nordestino e interiorano e, ao mesmo tempo, a repulsa em ser visualizado dentro de um contexto de conservadorismo religioso, bem comum a boa parte dos moradores dos setores mais vulneráveis socialmente e economicamente do Nordeste. Para eles o "fvck religion não é uma afronta, mas um enfrentamento" e, segundo o guitarrista Vini Martins, no mesmo material, o "fvck religion" tem como eixo o hardcore, death e o doom.

${ }^{10}$ Utilizamos aqui o gênero citado pelos componentes da banda em uma entrevista realizada através do perfil da banda Black Witch no Facebook. Este mesmo nome é utilizado no minidoc do canal Mosh Vid e disponível no endereço https://www.youtube.com/watch?v=8vqqKQl1uAo. Vale salientar que o "bong rock" não difere do "Stoner rock", também conhecido como "Stoner metal" e "Stoner doom". As bandas pioneiras deste gênero, que costuma mesclar características do rock music, heavy metal, psychedelic rock e acid rock foram as californianas Kyuss e Sleep. Atualmente a também californiana Queens of The Stone Age (QOTSA) é uma das principais referências midiáticas do Stoner globalmente, a banda foi fundada em 1996 e atualmente encontra-se ativa. O guitarrista da formação inicial da Kyuss Josh Homme é o fundador, vocalista e também guitarrista da QOTSA.
} 
Grosseiros/SP e a Horror Chamber/RS. As demais foram a potiguar Evil Razor (thrash metal) e a banda cearense tributo ao Black Sabbath, Embryo.

Como podemos observar o Valhalla surge nesta rede como um dos principais nódulos de integração. Sua atuação - enquanto ação dos atores - gira em torno de confraternizações, organizações de evento, ponto de encontro, referência de respeito entre os pares onde a confiança e a segurança de ser um local em que se possa ouvir, conversar amenidades ou intercambiar informações sobre shows locais/regionais e novidades envolta de bandas mundialmente conhecidas. Poderíamos também localizar tais características em outros bares na cidade, porém o que nos faz apresentar o Valhalla como recorte para enfrentarmos a ideia de cena musical deriva, entre outras, das identificações localizadas na noção e sua íntima relação com a cultura globalizante do rock e da anglofonia. Citamos o idioma britânico por haver um pressuposto da composição do gênero "heavy metal" ser executado em inglês, ou seja, cabe aqui a ideia de que o gênero musical tem a sua hegemonia na anglofonia, mas isto não significa afirmar um pleno domínio do idioma por parte dos seus adeptos e ouvintes. Há um processo de transculturação, sem excluir os processos de dominação, amplificado pela Internet.

Assim, os saberes, resultados destes mesmos processos transculturais, são negociações entre culturas caracterizadas pelas zonas de contato físicas ou virtuais (PRATT, 1992). Ou, como afirma Claudia de Lima Costa, é extremamente complexo e difícil "apontar a origem de um saber e suas múltiplas hibridizações, já que saberes sempre surgem nesses espaços assimétricos de relações de poder e são apropriados, traduzidos, ressignificados e redistribuídos, subvertendo qualquer visão binária entre Ocidente e seus outros" (COSTA, 2014, p. 932).

\section{Considerações quase finais ou em busca de uma nova epistemologia}

Esse nosso cuidado de não isolar o fenômeno também integra uma tentativa de analisar a cena musical ampliada. Sendo assim, além de entendermos as manifestações das cenas musicais a partir do que Straw (1991) nomeou de "Sistema de Articulação Universal", indicamos pensar em alguns outros "Sistemas de Articulação" que possam afetar diretamente e indiretamente o fluxo dos bares/cidades aqui pesquisados. Pensaremos assim inspirados em Appadurai (2004) onde o mesmo utilizou o termo "localidade" para se referir a elementos relacionais e contextuais. Ou 
seja, ele trabalha no campo das fronteiras fluidas preferindo esses dois elementos ao espaço propriamente dito. Observe a sua descrição sobre a "localidade":

\begin{abstract}
Vejo-a como uma qualidade fenomenológica complexa constituída por uma série de vínculos entre o sentido da imediaticidade social, a tecnologia da interactividade e a relatividade dos contextos. Esta qualidade fenomenológica, que se exprime em certos tipos de acção, socialidade e reprodutibilidade, é o principal predicado da localidade como categoria (ou objecto) que procuro explorar (APPADURAI, 2004, p. 237-238).
\end{abstract}

Estudar os bares tal como proposto neste estudo leva-nos inevitavelmente a esta rede fenomenológica complexa apontada por Appadurai (2004), na qual põe em camada e sem hierarquias os tipos de ação, socialidade e a reprodutibilidade (também visualizada pelos Sistema de Articulação de Will Straw), porém buscaremos neste último tópico visualizar a reprodutibilidade dentro de uma teia interna em que alimenta a cena e seus atores.

Sendo assim, inspirados em Haesbaert (2014), também trabalhamos com a ideia de "constelação de conceitos" onde há de forma bem profunda suas análises sobre territórios e suas multi/transterritorialidades, sugerimos visualizarmos e pensarmos neste trabalho a cena musical dentro de uma ideia similar. Em outras palavras, a nossa proposição é de que o nosso "o mapa de articulação" tenha em um de seus eixos o "Sistema de Articulação Universal" e logo abaixo dele o "Sistema de Articulação Regional", nos quais incluiremos outras inúmeras categorias de análise, as quais serão conectadas umas às outras. Vale ressaltar da impossibilidade delas (as outras categorias) serem excludentes entre si, pois todas têm igual valor e devemos evitar leituras hierarquizantes das categorias nas formações das cenas. Por isso, as categorias de análise possibilitam uma ampliação da visualização macro de onde possa vir a estar inserida a cena musical e, começaremos assim a tecer a teia interna que pode, não necessariamente, marcar presença (in) diretamente nos fluxos e composições dos bares investigados juntamente aos seus atores.

Enfim, quando investigamos as cenas musicais em cidades interioranas do Nordeste do Brasil, neste caso específico o Valhalla Rock Bar, a partir do questionamento geopolítico da centralidade dos estudos, por um momento, tínhamos como ponto de partida provocativo a geografia, a qual nos situa ou caracteriza enquanto região "periférica”. Quando nos debruçamos nas ideias de cena musical, começamos a observar que o nosso questionamento era legítimo, porém, a busca do entendimento do fenômeno estava indo numa rota de colisão exatamente com 
os nossos questionamentos. Ingenuamente, queríamos questionar o geopolítico, sem nos dar conta da importância e presença de outros elementos (idioma, bandas, meios de comunicação) e constatamos que não há como dissociar a geografia - como o uso do termo "periférico" do político, incluindo a formação do estado brasileiro - passando pela experiência colonialista, escravagista e classista - até os dias atuais.

Assim, ao retomar a ideia central de Irwin (1997 [1970]), a partir da qual o mesmo afirma que cena "refere-se a um conjunto de padrões seguidos por alguma coletividade de atores em vários momentos e locais em suas rotinas cotidianas" e em diálogo com outros pesquisadores, principalmente Straw (1991), gostaríamos de disponibilizar e de, digamos, pensar o entendimento de cena também a partir do compartilhamento de uma configuração de padrões de comportamento, na mesma perspectiva apontada por Will Straw (2015), quando se refere a mundos éticos moldados pela elaboração e pela manutenção de gostos, identidades e regras de comportamento em um grupo de atores, porém, vale acrescentar, não restritas a apenas uma cidade ou bairro.

Sugerimos assim que investigar bares e/ou outros espaços enquanto locais privilegiados da materialização da cena pode e deve ser ampliado ao incluir interconexões entre bairros, cidades e regiões nas atividades em torno da música. Podemos, desta forma, além de expandir e pensar a materialização de cenas musicais em realidades distintas das metrópoles, buscar observar esse fenômeno urbano dentro de um aspecto macro e regionalizado.

$\mathrm{Na}$ pesquisa sobre as cenas musicais interioranas (QUEIROZ, 2019), conseguíamos ao menos visualizar algo pulsante dos bares de cidades medianas. Era algo potente, mas que a literatura não nos ajudava, em sua completude, a investigar, a partir das perspectivas já discutidas na ciência. Porém, por um lado, também não visualizávamos a forte presença dos elementos globais de "homogeneização" ou, como aponta Motti Regev (2013), para um “cosmopolitismo estético", muitas vezes presente nos discursos euro-norte-americanos.

Ao investigar formas alternativas em que possamos incluir e não ter como premissa alguns elementos excludentes de cena musical no interior do Nordeste, buscamos pensar a cena das cidades interioranas a partir da teoria decolonialista. Dialogamos assim de forma mais próxima com o conceito de Luiz Rufino de "Regurgitar" (2016). Nesse interessante trabalho, Rufino se apropria do signo de Exu no Candomblé e pensa numa perspectiva de enfrentamento da 
colonialidade do ser e saber, bem como, o poder operante nas corporeidades afrodiaspóricas. Em outras palavras, Rufino (2016, p. 57-8) evoca as sabedorias transculturais do orixá Exu para exemplificar a "ação de tratamento do ato de regurgitar, que como tal, nunca entrega ou devolve aquilo que engoliu da mesma maneira". A transculturalidade evocada com o signo Exu nos é mais condizente com as cenas interioranas e mais próxima desse intenso trânsito cultural do que propriamente a menção do termo "cosmopolita", pois o decolonialismo vai além do "cosmopolitismo estético", o qual pressupõe uma conexão com um mundo global e uma desconexão das amarras locais, quando os atores se tornam uma espécie de cidadão do mundo.

Enfim, o decolonialismo nos faz lembrar e ressaltar as características singulares presentes nesta transculturalidade, levando-nos a pensar além da dicotomia e de dualidades intensivas entre os fenômenos midiáticos globais e suas características locais. Dessa forma, deslocamo-nos novamente para as inúmeras possibilidades que a transculturalidade pode convidar quando pensamos em pesquisas no campo da educação. Preferimos pensar numa mútua manifestação dos fenômenos ao mesmo tempo, sem um precisar anular o outro. Pensamos num regurgitar cultural tendo como pressuposto, também, a nossa formação sociológica, política, econômica, bem como o imenso e infindável gradiente de perfis distintos de atores a performarem nas instituições caras às cenas. E também tão caras nas dimensões epistemológicas e metodológicas das pesquisas em educação.

Em outras palavras estamos a realizar um exercício de repensar a cena musical a partir da nossa ótica latino-americana-nordestina-interiorana que, por consequência, amplia a ideia inicial de cena musical (STRAW, 1991; 2001; 2015), bem como nos coloca no mapa das discussões globais dos fenômenos urbanos de cena musical numa outra perspectiva. Ou seja, pensamos aqui numa perspectiva decolonial da noção de cena musical. Uma proposição a questionar a colonialidade das discussões sobre cena musical e, ao mesmo tempo, uma tentativa de inserção epistemológica onde sugerimos observar a diversidade de atores a frequentar e alimentar a cena. Como categoria analítica a presença de determinados perfis de atores alimenta e dá margens para visualizarmos as cenas musicais de metal não restritas a homens/brancos/cis e isoladas em um único ponto geográfico na cidade. Sendo assim, buscamos evitar discursos homogeneizantes e essencialistas, como já afirmamos, comuns em algumas abordagens estandartizados no campo das ciências humanas. 
Por fim, propomos pensar a cena musical decolonial como marco político/acadêmico. Neste trabalho, por exemplo, sugerimos ampliar a perspectiva de análise territorial, mesmo ao estudar um único bar, ao incluir as pequenas redes existentes as quais (retro) alimentam as materializações da cena musical na cidade de Mossoró/RN. Vale salientar que estamos a observar uma cidade no interior do Rio Grande do Norte, que, apesar de se configurar como polo regional econômico, distancia-se da realidade estruturada e de instituições consolidadas comumente localizadas em metrópoles.

Assim sendo, acreditamos na possibilidade de abrir margens para se pensar além das grandes cidades, metrópoles e do modelo euro-norte-americano e, da mesma forma, deixaremos por consequência algumas rotas de fuga para se pensar cenas musicais a partir de gêneros musicais não-anglófonos e/ou em outras territorialidades, bem como aberturas para se pensar outras manifestações culturais e outros perfis identitários.

\section{Referências}

APPADURAI, Arjun. Dimensões culturais da globalização: a modernidade sem peias. Lisboa: Editorial Teorema, 2004.

BLACK WITCH. Musicista/banda. 2015. Facebook. Disponível em: https://www.facebook.com/blackwitchbr/. Acesso em: 21 maio 2017.

CERTEAU, Michel. A invenção do cotidiano: 1 - artes de fazer. Petrópolis: Vozes, 2008.

COSTA, Cláudia Lima. Feminismos descoloniais para além do humano. Estudos Feministas, Florianópolis, v. 22, n. 3, p. 929-934, set./dez. 2014.

HAESBAERT, Rogério. Viver no limite: território e multi/transterritorialidade em tempos de insegurança e contenção. Rio de Janeiro: Bertrand Brasil, 2014.

HEAVENLESS. Musicista, banda. 2015. Facebook. Disponível em: https://www.facebook.com/heavenless666/. Acesso em: 21 maio 2017.

IRWIN, John. Notes on the status the concept subculture [1970]. In: THORNTON, Sarah; GELDER, Kenneth. The subcultures reader. New York: Routledge London, 1997. p. 66-70.

LASTING MAZE. Musicista/banda. 2014. Facebook. Disponível em: https://www.facebook.com/LastingMaze1/. Acesso em: 21 maio 2017.

LEMOS, André. A comunicação das coisas: teoria ator-rede e cibercultura. São Paulo: Anablume, 2013.

MORENO, Ana Carolina. Negros representam apenas $16 \%$ dos professores universitários. Rio de Janeiro: G1, 2018. Disponível em: https://g1.globo.com/educacao/guia-de-

carreiras/noticia/2018/11/20/negros-representam-apenas-16-dos-professores-universitarios.ghtml. Acesso em: 11 out. 2018.

PRATT, Mary L. Imperial eyes: travel writing and transculturaltion. New York: Routledge, 1992. 
QUEIROZ, Tobias Arruda. Valhalla, all black in e metal beer: repensando a cena musical a partir dos bares no interior do Nordeste. 276f. 2019. Tese (Doutorado em Comunicação) - Centro de Artes e Comunicação, Programa de Pós-Graduação em Comunicação, Universidade Federal de Pernambuco, 2019.

REGEV, Motti. Pop-rock music. Aesthetic Cosmopolitanism in Late Modernity. Nova Jersey: Polity Press, 2013.

REVANGER. Musicista/banda. 2015. Facebook. Disponível em: https://www.facebook.com/RevAnger01/. Acesso em: 21 maio 2017.

RISING RECORDS. Estúdio musical. 2013. Facebook. Disponível em: https://www.facebook.com/Risingmossoro. Acesso em: 21 maio 2017.

RUFINO, Luiz. Performances afro-diaspóricas e decolonialidade: o saber corporal a partir de Exu e suas encruzilhadas. Revista Antropolítica, Niterói, n. 40, p.54-80, jan./jun. 2016.

SAID, Edward. Figures, configurations, transfigurations. Race e Class, Califórnia, v. 32, n. 1, p. 116, 1990.

SAID, Edward. Orientalismo. São Paulo: Companhia das Letras, 2003.

SANT, Javier. Heavy metal in baghdad. 30 maio 2015. 1 vídeo (1h23m56s.). Disponível em: https://www.youtube.com/watch?v=vjC3VtR8GzY. Acesso em: 04 jan. 2019.

SANTOS, M. We do rock too: os percursos do gênero musical metal no movimento do rock angolano. 2018. Tese (Doutorado em Comunicação) - Programa de Pós-Graduação em Comunicação, Universidade Federal Fluminense, Niterói, 2018.

SKAYP MODELS. Skayp Alternativa. Facebook, disponível em: https://www.facebook.com/SkaypModels/, 2013. Acesso em 21 maio 2017.

STRAW, Will. Cenas culturais e as consequências imprevistas da políticas públicas. In: JANOTTI

JUNIOR. Jeder; SÁ, Simone Pereira de. Cenas musicais. São Paulo: Anadarco, 2013. p. 9-23.

STRAW, Will. Scenes and Sensibilities. Public, Toronto, n. 22/23, p. 245-257, fev. 2001.

STRAW, Will. Will Straw e a importância da ideia de cenas musicais nos estudos de música e comunicação. [Entrevista cedida a] Jeder Janotti Júnior. Revista E-Compós, Brasília, v. 15, n. 2, 2012.

STRAW, Will. Some things a scene might be. Cultural Studies, Ottawa, v. 29, n. 3, p. 476-485, 2015.

STRAW, Will. System of articulation, logics of change: scenes and communication in popular music.

Cultural Studies, Ottawa, v. 5, n. 3, p. 368-388, 1991.

VARAS-DÍAZ, Nelson. The Distorted Island: Heavy Metal music and community in Puerto Rico. 1 vídeo (1h57m52s.). 6 nov. 2015. Disponível em: https://www.youtube.com/watch?v=zKe5TMPGTqE. Acesso em: 13 jan. 2019.

VPRO WORLD SERIES. Islamic metal band in Indonesia - The Westerners. 5 mar. 2018. Disponível em: https://www.youtube.com/watch?v=0fhp2sgaON4. Acesso em: 13 jan. 2019. 